\author{
Cracow Indological Studies \\ Vol. XX, No. 2 (2018), pp. 283-290 \\ https://doi.org/10.12797/CIS.20.2018.02.13
}

\title{
Anshu Malhotra, Piro and the Gulabdasis: Gender, Sect and Society in Punjab. xlviii + 358 pp. Delhi: Oxford University Press, 2017.-—Reviewed by Monika Browarczyk (Adam Mickiewicz University, Poznań)
}

Born in Punjab, which at that time was ensconced in the Sikh Empire of Ranjit Singh, probably in the third decade of the $19^{\text {th }}$ century; died in 1872 in the same region, then already a part of the British India; buried with her spiritual master in Chathianwala in a part of Punjab, which lies in today's Pakistan. Piro, a Muslim low-caste prostitute who turned into a poet, a chief worshipper of a sect headed by Gulabdas (1809-1873), and, for some of its followers, its revered female master. An author of Ik Sau Sațh Käfiāri (or One Hundred and Sixty Kafis) and some other verses, popular Bhakti compositions of Punjab, that can be construed as pre-modern but, nonetheless, autobiographical narrative.

Piro's elusive voice - "recondite and elliptical in its allegorical, allusive language, yet forthright and scathing in its condemnation of social codes of caste, gender and religious behaviour" (Malhotra 2017: xvii) is the principal research interest of Anshu Malhotra's impressive and ambitious monograph, Piro and the Gulabdasis: Gender, Sect and Society in Punjab. For in this study it is Piro and her compositions that amalgamate the historical narrative of various discourses of the past and the present, of the religious and the sectarian, of the socially inclusive and the socially exclusive, and of gendered in Punjab. Malhotra foregrounds her study in the following manner (ibid.: xix), "We thus get glimpses of Punjab and its social and cultural life through stories 
of the sect that begin sometime in the latter part of Ranjit Singh's rule; cast a fugacious glance at the colonial era through the public life of one man and try to unravel Punjabi disposition for social change as well as for replenishing cultural habits by looking at aspects of the Gulabdasi dera in our own time." 1

Reintroducing Piro's legacy of preserved written manuscripts becomes apposite to the history of northern India, and Punjab in particular, as " $[\mathrm{t}]$ he famed fertile land of Punjab had proven to be singularly barren in fructifying its women expressions in written and published forms (...)" (ibid.: xvii), a telling observation made by Malhotra during her earlier studies of high-caste Hindu and Sikh women.

Anshu Malhotra, at present an associate professor at the Department of History, University of Delhi, has had a proven record of scrutinizing Punjab's history, starting from her PhD of 1998 at the School of Oriental and African Languages, titled Pativratas and Kupattis: Gender, Caste and Identity in Punjab-1870s-1920s, through a monograph, Gender, Caste, and Religious Identities: Restructuring Class in Colonial Punjab (published in 2002; and again in 2004 and 2009), and to a volume co-edited by Farina Mir, Punjab Reconsidered: History, Culture, and Practice (2012), in addition to numerous research articles and conference papers pertaining to this subject. Her academic work reflects her attentiveness to the nuanced reading of Punjab's past that centres on a number of influences at work such as gender, caste, religion and class.

My acquaintance with Malhotra's groundwork on Piro goes back to a volume on autobiographical writings by women and female impersonators from the Indian subcontinent, or Speaking of the Self. Gender, Performance and Autobiography in South Asia, which she co-edited with Siobhan Lambert-Hurley in 2015 (Indian edition of the book under the same title has been published by Zubaan in 2018).

1 Cf. Malhotra 2017: xxiv-v: "The term 'dera' conjures encampment, it signals the spatiality of abode, the domicile of doctrinally like-minded people who are institutionally independent." 
“Performing a Persona. Reading Piro's Kafis", a chapter on Piro's autobiographical verses authored by Malhotra (Malhotra 2015: 205-229) was included in the collection and that is how many a reader was notified of the extraordinary life of Piro and her equally bewildering versified autobiographical tale. In the said chapter, Malhotra has contextualised compositions and life of Piro along the following lines, "adapting and intersecting Bhakti, Sikh, and Sufi inheritance to her own existential needs at one level, and sifting them for her philosophical contemplations on the other" (ibid.: 207), and focused on "multiple conditions of liminality that defined Piro's life - of occupation, gender, caste - combined with the sense of feeling persecuted" (ibid.: 226).

The methodologically and academically grounded volume under review here, Piro and the Gulabdasis: Gender, Sect and Society in Punjab, is a much-needed comprehensive study of the elusive voice of an unusual woman set against the well-crafted and eruditely narrated historical backdrop of Punjab in three consecutive periods (pre-modern, colonial and contemporary). In this analysis too, Malhotra's focus remains on the interplay between such factors as caste, gender, sect, and religion. She outlines not only variations in multiple accounts of history of Punjab, but drawing from Peter Burke, ponders over 'micronarrative' of Piro's life and 'microhistory' of the Gulabdasis, which more often than not does not contain factual details supported by widely available historical evidence but comes across in bits and pieces from various texts. In Malhotra's words (Malhotra 2017: xxii): “(...) the intention in this study is to not try too hard to fill in the gaps of her [i.e. Piro's] life as much as try to comprehend it by attempting to apprehend the processes around it."

Equipped with methodological tools of a trained historian, Malhotra works not only on documents from the sectarian records and from the colonial archives, but also on poetry and orature etc. Her source materials come from several languages, i.e. Punjabi, Hindi, Urdu, and English. The inquiry is forwarded by a section "Self, Sect, and the Society: An Introduction" (ibid.: xvii-xlviii). In Part I of the book, Malhotra examines various accounts of Gulabdas' life in an attempt 
to trace the person behind the unsympathetic accounts of his adversaries and reverent opinions of the sect's hagiographers (Chapter 1. "Guru Gulabdas: A Savant Monist or a Deviant Maverick?", ibid.: 3-54). While discussing the theology of the Gulabdasis, she intends to answer why in different documents the sect was variously denominated as "nastak (atheists), mauji (pleasure-seekers), Charvaki (materialists), Sarbhangi (against caste and pollution), aghori (tantra-inspired sect) and even Sufi" (ibid.: 39). The question of the Gulabdasis' take on morality is discussed in the concluding section of the first part.

In Part II that comprises of four chapters, Malhotra introduces Piro and her compositions (Chapter 2. "A Life-Story in an Autobiographical Fragment", ibid.: 55-91), in the light of self-crafted religious identity of an ex-Muslim, low-caste, woman convert into a syncretistic tradition of the Gulabdasis (Chapter 3. "Agnostic Religiosity, Gendered Self, and a Conversion Narrative", ibid.: 92-122). Malhotra accentuates gaps and allusions in Piro's auto-expressive verses (ibid.: 58): "Piro's 'life story' is not the story of Piro's life; far from it, for she remains elusive. What we know of her comes mainly from elliptical references in her other works besides 160 Kafis, which obsesses over a chain of events that are triggered by her momentous decision to become a disciple of Gulabdas. Thus too the 160 Kafis are fragmentary, not only in material shape of the manuscript when it was discovered, but also because for all the salience of the related incidents, they cover a miniscule fragment of her life. We grapple with disjointed references to create some template of her life, to fill up the holes in what comes across as a fragmented life, particularly in her early years."

While discussing the fragmentary autobiography inscribed in Piro's verses, Malhotra foregrounds the 'performative' aspect of her autobiographical act (ibid.: 71). The subjects of self-referential texts in premodern India - of Babar, Jahangir, Banarsidas, Mir Taqui Mir, Ananda Ranga Tillai - and the construction of women's identityin writings of Jahanara Begum, Maha Laqa Bai Chanda, Bahinabai, Rassudri Devi-are also discussed. The narrative of Piro's conversion and of the dramatic circumstances of her later abduction by her 
oppressors and escape to re-join her guru's abode in Chathianwala are being scrutinised, along with her gendered identity. Malhotra concludes (ibid.: 122): "[Piro] critiques outwardly inclined male public religiosity as inapplicable to women, we see her having arrived at a view that an interiorised piety was worth aspiring to, and, in fact, amenably suitable for women."

The following section of the volume is dedicated to a study of Piro's low-caste and Muslim background in relation with the Bhakti modes of religiosity that aim at embracing multiple faiths and numerous social groups, including those of the lowest social standing (Chapter 4. "A Low-Caste Muslim Prostitute and Bhakti Religiosity: Cultural Imaginary and the Ability to Imagine Otherwise", ibid.: 123-171). In Piro's tale of her life "sexually charged" female Bhaktas of lowcaste (Kubjan, Shabari, and Jivanti) are staged centrally as they provide the vantage point of argument for availability of salvation on the path of Bhakti to women in general, and those of 'dubious character' and low social standing in particular. The references to Mira, the female icon of the North Indian Bhakti and Kabir, the low-caste voice of the Nirguna tradition are of importance to Piro for proving the allencompassing approach of Bhakti. Malhotra (ibid.: 130-131) shows in this section that: "the inherent subversive tendencies of bhakti were sought out to be exploited by Piro, who pushed for more radical possibilities opened by it, seeking to widen its ambit to include a low-caste woman, a prostitute, and a Muslim (...)" and highlights "the manner in which bhakti's cultural imaginary provided Piro with a legacy that she deftly employed, establishing her autonomous agency."

In the last chapter of this part (Chapter 5. "Miracles and Women Bhakta's: Understanding Piro's Agency", ibid.: 172-200), Malhotra deliberates over narratives of miracles and their prominence in episodic autobiographical tales of Bahinabai and Piro. Arguing that they were essential in defining the agency of women authors, she reasons drawing from Saba Mahmood and others (ibid.: 175): "Agency here is seen to connote self-reflexivity, one that sees the individual as autonomous, active and in charge, though imbricated in multiple impinging 
and power-informed cultural formation." However, (ibid.: 176): "The pervasiveness of cultural norms - whether in governing lived perspectives or (re)shaping memoirs - complicates further the notion of ostensibly unfettered individual agency. This suggests that both the represented self and its reception are historically contingent, shaped by cultural norms that govern societies."

Foregrounding the tale of Piro as the narrative of those marginalised but aiming at taking more centralised position (i.e. "from margin caste, gender, profession to respectable and acceptable", ibid.: xviiii), Malhotra, consequently, in the next section, traces the life and writings of Giani Ditt Singh. This analysis opens Part III of the monograph (Chapter 6. "Caste in the Colonial Sphere. The Conundrum of Sant Ditta Ram/Giani Ditt Singh", ibid.: 201-236) and follows the transition of the Gulabdasi preacher, Sant Ditta Ram (d. 1901), into an active member of the Arya Samaj and of the Lahore Sikh Sabha, renamed Giani Ditt Singh. His life story is at present being reworked by the dalit discourse into a narrative of a dalit hero, though Malhotra in the analysis of his writing points out his complex position on the question of caste and argues (ibid.: 236): "Thus, in the corpus of Singh's writings we find ambiguity, vacillation, and fickleness in maintaining a single, coherent line of reform."

Interestingly, Malhotra writes on appropriation of the story of Piro and Gulabdas by the Punjabi theatre, where she discovers attempts of staging Piro as an important female persona in the development of the Punjabi Bhakti tradition (Chapter 7. "Theatre of the Past: Re-presenting the Past in Different Genres”, ibid.: 237-178). Along with the plays she investigates also some devotional literature on Piro and academic studies to "(...) argue that the circulation of varied discourses in the mundane world, the heteroglossia of utterances that impinge on us every day in multiple ways, plays a role in shaping what we choose to write or study. That is to say, one's own present impacts the way in which we study the past. (...) The historian's voice is one among many competing to speak and be heard, though the privilege of being situated in the academia, ands as connoisseurs of the past, 
historians might be keener to show that "their explanations are better than competing explanations' [Raymond Martin 2001]".

In addition, Malhotra provides readers with the socio-anthropological study of contemporary attempts at the revival of the Gulabdasis in north India. She describes elements of its present cult with ceremonies and festivals being invented and purposefully arranged around Gulabdas' and Piro's lives and neo-sacralised sites, which are to substitute for the venerated places of the Gulabdasis, which are situated in Pakistan (Chapter 8. "Fantassticating Fables, Sacrilizing Spaces and Remaking Rituals: The Gulabdasis at a Contemporary Moment", ibid.: 279-324).

It is pertinent to note that the in-depth analysis of the syncretistic sect - influenced by advaita monism further filtered by the Bhakti, Sikh and Sufi traditions - that heralded importance of tolerance towards all religions and faiths and was open to members of all castes and genders, gathers considerable momentum in today's India with the heightened tensions among religious communities and castes. Moreover, it is so because Malhotra, simultaneously to skilful reconstruction of the history of Piro, Gulbdas and the Gulabdasis, introduces the audience to a nuanced process of recreating the past on the basis of multiple fragmentary sources with rigorous scholarly determination of a historian contrary and resistant to the contemporary state-imposed efforts of somewhat partisan and homogenous rewriting of Indian history.

\section{References}

Malhotra, A. 2002. Gender, Caste, and Religious Identities: Restructuring Class in Colonial Punjab. New York: Oxford University Press.

— and F. Mir (eds.). 2012. Punjab Reconsidered: History, Culture, and Practice. New Delhi: Oxford University Press.

- and S. Lambert-Hurley (eds.). 2015. Speaking of the Self: Gender, Performance, and Autobiography in South Asia. London: Duke University Press. 
—. 2015. Performing a Persona. Reading Piro's Kafis. In: A. Malhotra and S. Lambert-Hurley (eds.). 2015. Speaking of the Self: Gender, Performance, and Autobiography in South Asia. London: Duke University Press: 205-229. https://doi.org/10.1215/9780822374978-009.

Williams, T., A. Malhotra and J.S. Hawley (eds.). 2018. Text and Tradition in Early Modern North India. London: Oxford University Press. 